\title{
Norepinephrine Transporter Blockade can Normalize the Prepulse Inhibition Deficits Found in Dopamine Transporter Knockout Mice
}

\author{
Motoyasu Yamashita', Setsu Fukushima', Hao-wei Shen², F Scott Hall', George R Uhl ${ }^{3}$, Yohtaro Numachi', \\ Hideaki Kobayashi' and Ichiro Sora*1,2,3 \\ 'Department of Psychobiology, Tohoku University Graduate School of Medicine, Sendai, Miyagi, Japan; ${ }^{2}$ Department of Molecular Psychiatry, \\ Tokyo Institute of Psychiatry, Tokyo, Japan; ${ }^{3}$ Molecular Neurobiology Branch, Intramural Research Program, National Institute on Drug Abuse, \\ NIHIDHHS, Baltimore, MD, USA
}

\begin{abstract}
Dopamine transporter knockout (DAT KO) mice display deficits in sensorimotor gating that are manifested by reduced prepulse inhibition (PPI) of the acoustic startle reflex. Since PPI deficits may model some of the cognitive dysfunctions identified in certain neuropsychiatric patients, we have studied the effects of transporter blockers on PPI in wild-type and DAT KO mice. Treatments with High dose psychostimulants that block DAT as well as the norepinephrine (NET) and serotonin (SERT) transporters (60 mg/kg cocaine or methylphenidate) significantly impaired PPI in wild-type mice. By contrast, these treatments significantly ameliorated the PPI deficits observed in untreated DAT KO mice. In studies with more selective transport inhibitors, the selective NET inhibitor nisoxetine (I0 or $30 \mathrm{mg} / \mathrm{kg}$ ) also significantly reversed PPI deficits in DAT KO mice. By contrast, while the SERT inhibitor fluoxetine (30 mg/kg) normalized these PPI deficits in DAT KO mice, citalopram (30 or $100 \mathrm{mg} / \mathrm{kg}$ ) failed to do so. The 'paradoxical' effects of cocaine and methylphenidate in DAT KO mice are thus likely to be mediated, at least in part by the ability of these drugs to block NET, although serotonin systems may also have some role. Together with recent microdialysis data, these results support the hypothesis that prefrontal cortical NET blockade and consequent enhancement of prefrontal cortical extracellular dopamine mediates the reversal of PPI deficits in DAT KO mice.

Neuropsychopharmacology (2006) 31, 2132-2139. doi: 10.1038/sj.npp. I 301009; published online II January 2006
\end{abstract}

Keywords: dopamine transporter; norepinephrine transporter; serotonin transporter; knockout mice; prepulse inhibition; startle

\section{INTRODUCTION}

Microdialysis studies suggest that dopamine transporter knockout (DAT KO) mice exhibit striatal levels of extracellular dopamine (DA), under basal conditions, that are about 10 times higher than wild-type levels while prefrontal cortical levels are similar to those found in wild-type animals (Shen et al, 2004). DAT KO mice exhibit numerous behavioral alterations that can be linked to abnormal dopaminergic function that include hyperlocomotion and perseverative behaviors (Sora et al, 1998; Ralph et al, 2001). High doses of psychostimulant, monoamine transporter inhibitors, and/or monoamine releasers that produce

\footnotetext{
*Correspondence: Dr I Sora, Department of Psychobiology, Tohoku University Graduate School of Medicine, I-I Seiryo-machi, Sendai, Miyagi 980-8574, Japan, Tel: +81 22717 7808, Fax: +81 22717 7809, E-mail: isora@mail.tains.tohoku.ac.jp

Received 21 June 2005; revised 28 October 2005; accepted 8 November 2005

Online publication: 15 November 2005 at http://www.acnp.org/ citations/Npp | | | 505050378/default.pdf
}

marked motor stimulation in wild-type mice can produce paradoxical inhibitory effects on locomotor activity in DAT KO mice under some conditions (Gainetdinov et al, 1999). However, the effects of psychostimulants and transporter blockers on other tasks, including sensorimotor gating, have not been as thoroughly evaluated in DAT KO mice.

DAT KO mice display consistent deficits in an operational task of sensorimotor gating, prepulse inhibition of the acoustic startle reflex (PPI; Ralph et al, 2001; Barr et al, 2004). PPI refers to the reduction in the amplitude of the startle reflex that occurs when a brief, subthreshold stimulus immediately precedes a startle stimulus (Hoffman and Ison, 1980). PPI deficits are observed in several psychiatric disorders, especially schizophrenia, but also other disorders thought to disrupt cortico-striatal circuits, eg attention deficit hyperactivity disorder (ADHD) in the given conditions, (Braff et al, 2001; Swerdlow et al, 2001). This impairment of sensorimotor gating has been postulated to reflect at least some portion of the cognitive dysfunction observed in schizophrenia (Braff et al, 2001). 
Acute treatment with selective $\mathrm{DA}_{2}$ receptor antagonists (Ralph et al, 2001) or selective serotonin 5- $\mathrm{HT}_{2 \mathrm{~A}}$ antagonists (Barr et al, 2004) can normalize PPI in DAT KO mice. The mechanisms by which these drugs restore PPI in DAT KO mice are likely to be mediated by direct actions on monoamine receptors. However, indirect effects that would result from monoamine transport inhibition (eg psychostimulants like cocaine or methylphenidate) on PPI in DAT KO mice is not known, but would be of substantial interest given the clinical effects of psychostimulants in schizophrenia (Laruelle and Abi-Dargham, 1999) and ADHD (Fone and Nutt, 2005). Thus, this paper determines whether psychostimulants could improve sensorimotor gating deficits reflecting cognitive dysfunctions in DAT KO mice, similar to the effects of such drugs on hyperlocomotion (Gainetdinov et al, 1999). Furthermore, this paper will determine which monoamine transporter might mediate such effects. Reuptake inhibitors have various degrees of selectivity for monoamine transporters, as well as other molecular targets, and thereby modulate extracellular monoamine levels in region-specific manners (Shen et al, 2004). We now report evaluation of PPI in DAT KO and wild-type mice and its modulation by the nonspecific monoamine transporter inhibitors cocaine and methylphenidate, the selective serotonin transporter (SERT) inhibitors fluoxetine and citalopram, and the selective norepinephrine transporter (NET) inhibitor nisoxetine.

Cocaine is a nonspecific transport inhibitor (ie, DAT, SERT, and NET inhibitor), although its binding affinity for NET is rather weak compared to nisoxetine (Paczkowski and Bryan-Lluka, 2002). Methylphenidate is also a nonspecific transport inhibitor, with a binding affinity for NET that is not much more than cocaine, and a binding affinity for SERT that is extremely weak (Gatley et al, 1996). Fluoxetine is a selective SERT inhibitor and the binding affinity for SERT differs little from citalopram. Although the binding affinity of fluoxetine at NET is very weak compared to nisoxetine, it presents about 30 times stronger binding affinity for the $5-\mathrm{HT}_{2 \mathrm{C}}$ receptor than citalopram (Owens et al, 2001). Citalopram is also a selective SERT inhibitor, with a binding affinity for NET that is about 10 times weaker than that of fluoxetine (Owens et al, 2001). Nisoxetine is a selective NET inhibitor and shows very low binding affinity for SERT (Orjales et al, 2003).

\section{MATERIALS AND METHODS}

\section{Subjects}

Male DAT KO mice (Sora et al, 1998) were bred at the Animal Laboratory Institute of Tohoku University Graduate School of Medicine and maintained on a mixed genetic background combining C57BL/6 and 129Sv/J mouse strains. Offsprings from heterozygote crosses were weaned at 28 days postnatal and housed in groups of two to five (segregated by sex), in a temperature- and light-controlled colony (lights on at 0800 hours, lights off at 2000 hours), with food and water available ad libitum. Mice were genotyped using multiplex polymerase chain reaction methods on DNA extracted from tail biopsies, as previously described (Shen et al, 2004). Behavioral testing was conducted between 8 and 16 weeks of age. Separate cohorts of mice were used for different experiments. All animal experiments were performed in accordance with the Guidelines for the Care of Laboratory Animals of Tohoku University Graduate School of Medicine.

\section{Drugs}

Drugs were dissolved in $0.9 \% \mathrm{NaCl}$ solution, and were administered intraperitoneally in a volume of $10 \mathrm{ml} / \mathrm{kg}$. Cocaine $\mathrm{HCl}$ (COC) was supplied by Takeda Pharmaceutical Co., Japan. Methylphenidate $\mathrm{HCl}$ (MPO) was supplied by Novartis Pharma KK, Japan. Fluoxetine HCl (FLX), citalopram $\mathrm{HBr}$ (CTP), and nisoxetine $\mathrm{HCl}$ (NSX) were obtained from Sigma, Japan. No published studies have documented the effects of acute cocaine, methylphenidate, fluoxetine, citalopram, or nisoxetine on PPI in male mice. Hence, to determine dose ranges, we primarily consulted previous data on locomotor activity effects of these drugs in wild-type and DAT KO mice (Gainetdinov et al, 1999). Since effective doses may differ between locomotion and prepulse inhibition, preliminary studies were performed. Based on the preliminary results, effective doses of each drug (described below) or dose intervals were determined.

\section{Apparatus}

Startle chambers (SR-LAB, San Diego Instruments, San Diego, CA) were used to measure the startle response. Each chamber consisted of a nonrestrictive Plexiglas cylinder mounted on a frame inside a lighted, ventilated box $\left(35 \times 35 \times 47.5 \mathrm{~cm}^{3}\right)$. Movement within the cylinder was detected by piezoelectric accelerometers attached to the cylinder's bottom. Force detected by the accelerometer was converted into analog signals that were digitized and stored electronically. In all experiments, 65 readings were recorded at $1 \mathrm{~ms}$ intervals beginning at stimulus onset; the average amplitude was used to describe the acoustic startle response. A high-frequency loudspeaker inside the chamber, mounted above the cylinder, generated broadband background noise and acoustic stimuli, which were controlled by the SR-LAB software system and interface. Sound levels (dB (A) scale) and accelerometer sensitivity were calibrated routinely, as described previously (Dulawa et al, 1997; Geyer and Dulawa, 2003).

\section{Experimental Procedure}

Experiments were conducted using previously reported methods (eg Geyer and Dulawa, 2003). For acoustic startle experiments, mice were tested initially for baseline PPI and pseudo-randomly assigned to drug treatment groups based on these measurements. For the main experiments, mice were treated with vehicle (VEH) or drug 10 or $30 \mathrm{~min}$ before testing depending on the drug tested (see below). Experimental sessions consisted of a 5 min acclimatization periods with $65 \mathrm{~dB}$ broadband background noise followed by PPI sessions. Sessions consisted of five different trial types: no stimulus trials (nostim); startle pulse alone, $40 \mathrm{~ms}$ duration at $120 \mathrm{~dB}$ (p120); and three prepulse + pulse trials, $20 \mathrm{~ms}$ duration prepulse at $68 \mathrm{~dB}(\mathrm{pp} 3), 71 \mathrm{~dB}(\mathrm{pp} 6)$, or $77 \mathrm{~dB}$ (pp12), followed by a $40 \mathrm{~ms}$ duration startle stimulus at $120 \mathrm{~dB}$ after a $100 \mathrm{~ms}$ delay. The nostim trial consisted of 
only background broadband noise. All test sessions started and concluded with six presentations of the p120 trial, while the remainder of the session consisted of 12 presentations of the p120 trial type, 10 presentations of the nostim, the pp3, pp6, and pp12 trial types, in a pseudorandom order, with varying intertrial intervals (mean $15 \mathrm{~s}$, range 8-23 s). Each animal was tested on a PPI session for 21 min with a total of 64 trials.

Cocaine treatment. Male wild-type and DAT KO mice were used in a between-subjects dose design, with each subject receiving either saline (wild-type $n=10$, DAT KO $n=10$ ), cocaine $30 \mathrm{mg} / \mathrm{kg}$ (wild-type $n=11$, DAT KO $n=13$ ), or cocaine $60 \mathrm{mg} / \mathrm{kg}$ (wild-type $n=11$, DAT KO $n=10$ ) administered i.p. $10 \mathrm{~min}$ before testing.

Methylphenidate treatment. Male wild-type and DAT KO mice were used in a between-subjects dose design, with saline (wild-type $n=10$, DAT KO $n=9$ ), methylphenidate $30 \mathrm{mg} / \mathrm{kg}$ (wild-type $n=17$, DAT KO $n=10$ ), or methylphenidate $60 \mathrm{mg} / \mathrm{kg}$ (wild-type $n=11$, DAT KO $n=11$ ) administered i.p. $30 \mathrm{~min}$ before testing.

Fluoxetine treatment. Male wild-type and DAT KO mice were used in a between-subjects dose design. Saline (wildtype $n=10$, DAT KO $n=10$ ), fluoxetine $10 \mathrm{mg} / \mathrm{kg}$ (wild-type $n=14$, DAT KO $n=10$ ), or fluoxetine $30 \mathrm{mg} / \mathrm{kg}$ (wild-type $n=12$, DAT KO $n=10$ ) was administered i.p. $30 \mathrm{~min}$ before testing.

Citalopram treatment. Male wild-type and DAT KO mice were used in a between-subjects dose design. Saline (wildtype $n=10$, DAT KO $n=10$ ), citalopram $30 \mathrm{mg} / \mathrm{kg}$ (wildtype $n=10$, DAT KO $n=10)$, or citalopram $100 \mathrm{mg} / \mathrm{kg}$ (wild-type $n=11$, DAT KO $n=10$ ) was administered i.p. $30 \mathrm{~min}$ before testing.

Nisoxetine treatment. Male wild-type and DAT KO mice were used in a between-subjects dose design. Saline (wildtype $n=12$, DAT KO $n=11$ ), nisoxetine $3 \mathrm{mg} / \mathrm{kg}$ (wild-type $n=13$, DAT KO $n=13$ ), nisoxetine $10 \mathrm{mg} / \mathrm{kg}$ (wild-type $n=12$, DAT KO $n=11$ ), or nisoxetine $30 \mathrm{mg} / \mathrm{kg}$ (wild-type $n=14$, DAT KO $n=11$ ) was administered i.p. $30 \mathrm{~min}$ before testing.

\section{Data and Statistical Analysis}

Prepulse inhibition was calculated as a percentage score for each prepulse intensity using the following equation: $\% \mathrm{PPI}=100-\{($ startle response for prepulse + pulse trials (pp3, pp6, or pp12))/(startle response for pulse alone trials $(\mathrm{p} 120)) \times 100\}$. The startle magnitude was calculated as the average of all pulse alone (p120) trials, excluding the first six and last six p120 trials in each session. Data were analyzed using the SPSS statistical package (SPSS for Windows, SPSS Inc., Tokyo, Japan). The effects of drug treatments on PPI and startle data were submitted to analysis of variance (ANOVA) with the between-subjects factors of drug treatment (DRUG) and GENOTYPE (wildtype $v s$ DAT KO), and the within-subjects factor of prepulse intensity (INTENSITY). For brevity, main effects of prepulse intensity will not be discussed because they were always significant. Where ANOVA indicated significant effects of one or more factors, Tukey HSD tests of individual mean differences were conducted for post hoc analysis. The habituation of the startle response was analyzed by grouping the startle trials into four blocks (BLOCK): six pulse alone trials ( $p 120)$ each, in order of presentation, and measuring the decrease of startle magnitude across BLOCK. Repeated ANOVAs always revealed significant main effects of BLOCK, indicating habituation of the startle response, but no significant DRUG $\times$ BLOCK and GENOTYPE $\times$ BLOCK interactions were found except a significant GENOTYPE $\times$ BLOCK interaction for fluoxetine treatment, which may reflect impairment of startle habituation in DAT KO mice (data not shown).

\section{RESULTS}

\section{Overall Results}

After saline treatment, significant PPI deficits were observed in DAT KO mice compared to wild-type mice in all experiments (Figures 1-5), findings consistent with prior reports (Ralph et al, 2001; Barr et al, 2004). Cocaine and methylphenidate $(60 \mathrm{mg} / \mathrm{kg})$ treatments significantly impaired PPI in wild-type mice. However, by contrast to these impairments observed in wild-type mice, these treatments normalized PPI deficits in DAT KO mice (Figures 1 and 2). Fluoxetine, citalopram, and nisoxetine treatments did not significantly alter PPI in wild-type mice (Figures 3-5). However, 10 and $30 \mathrm{mg} / \mathrm{kg}$ nisoxetine and $30 \mathrm{mg} / \mathrm{kg}$ fluoxetine treatments normalized PPI deficits in DAT KO mice (Figures 3 and 5), and 30 and $100 \mathrm{mg} / \mathrm{kg}$ citalopram treatment did not significantly alter PPI in DAT KO mice (Figure 4).

\section{Effects of Cocaine on PPI and Acoustic Startle}

ANOVA of baseline data revealed a significant GENOTYPE effect on PPI $(\mathrm{F}(1,18)=27.97 ; p<0.001)$; DAT KO mice displayed significantly reduced levels of PPI compared to

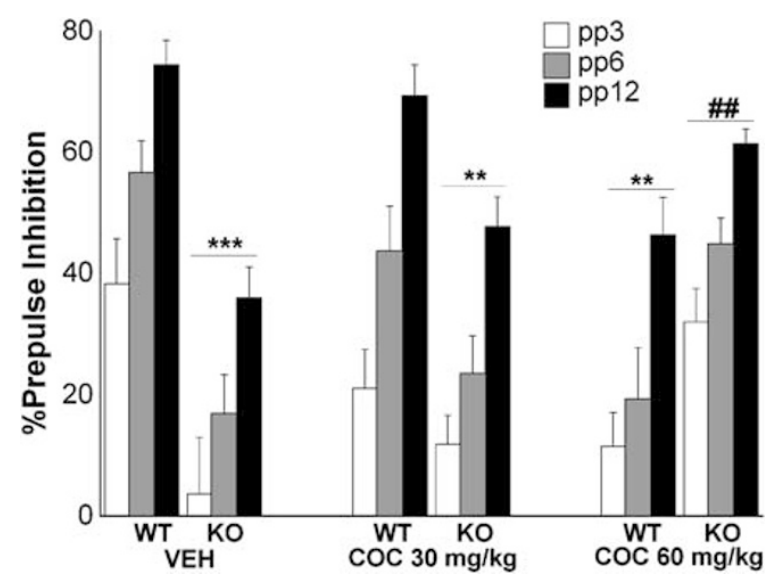

Figure I Prepulse inhibition (PPI) in wild-type mice (WT) and dopamine transporter knockout mice (KO) after administration of vehicle (VEH), $30 \mathrm{mg}$ $\mathrm{kg}$ cocaine (COC), or $60 \mathrm{mg} / \mathrm{kg}$ cocaine (COC); $\mathrm{KO} \mathrm{VEH} \mathrm{displayed}$ significantly reduced PPI compared with WT VEH. Although $60 \mathrm{mg} / \mathrm{kg}$ COC treatment significantly impaired PPI in WT VEH, it significantly reversed $\mathrm{PPI}$ deficits in $\mathrm{KO} \mathrm{VEH}$. \%PPI values represent mean \pm SEM. $* * * 2<0.01$, **** $p<0.00$ I compared with WT VEH; ${ }^{\# \#} p<0.0$ I compared with KO VEH. 


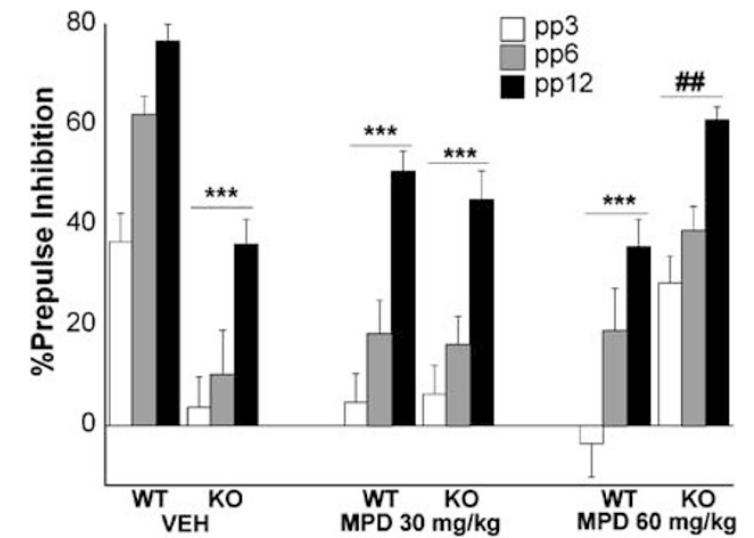

Figure 2 Prepulse inhibition (PPI) in wild-type mice (WT) and dopamine transporter knockout mice (KO) after administration of vehicle (VEH), $30 \mathrm{mg} / \mathrm{kg}$ methylphenidate (MPD), or $60 \mathrm{mg} / \mathrm{kg}$ methylphenidate (MPD); $\mathrm{KO} \mathrm{VEH}$ displayed significantly reduced PPI compared with WT VEH. Although $30 \mathrm{mg} / \mathrm{kg}$ or $60 \mathrm{mg} / \mathrm{kg}$ MPD treatment significantly impaired PPI in WT VEH, 60 mg/kg MPD significantly reversed PPI deficits in KO VEH. \%PPI values represent mean \pm SEM. ***** $p<0.00$ I compared with WT VEH; $\#$ \#\# $<0.01$ compared with $\mathrm{KO} \vee \mathrm{VEH}$.

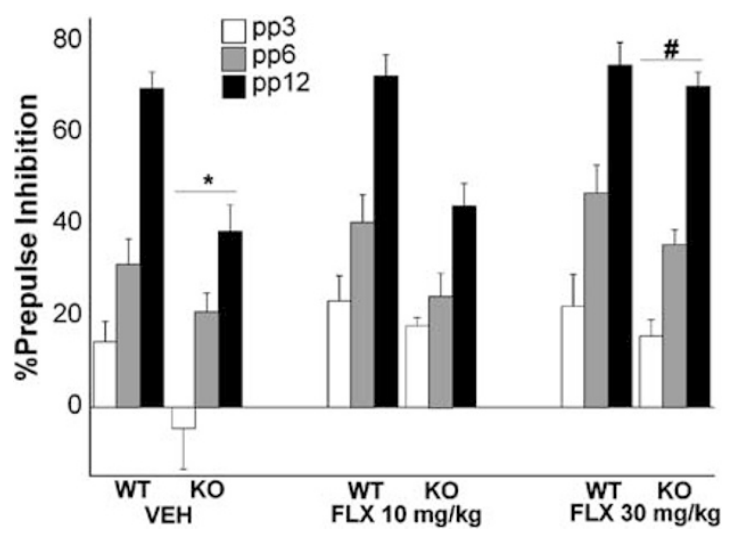

Figure 3 Prepulse inhibition (PPI) in wild-type mice (WT) and dopamine transporter knockout mice ( $\mathrm{KO}$ ) after administration of vehicle $(\mathrm{VEH})$, $10 \mathrm{mg} / \mathrm{kg}$ fluoxetine (FLX), or $30 \mathrm{mg} / \mathrm{kg}$ fluoxetine (FLX); KO VEH displayed significantly reduced PPI compared with WT VEH. FLX $(30 \mathrm{mg} /$ $\mathrm{kg}$ ) treatment significantly reversed PPI deficits in $\mathrm{KO} \mathrm{VEH}$ without significantly affecting PPI in WT VEH. \%PPI values represent mean \pm SEM. ${ }^{*} p<0.05$ compared with WT VEH; ${ }^{*} p<0.05$ compared with $\mathrm{KO}$ VEH.

wild-type mice after saline treatment (Figure 1). Cocaine $(60 \mathrm{mg} / \mathrm{kg})$, a nonspecific monoamine transport inhibitor, significantly reduced PPI in wild-type mice compared with saline treatment. Interestingly, cocaine $(60 \mathrm{mg} / \mathrm{kg})$ increased PPI in DAT KO mice compared to saline treatment (Figure 1). In addition to a significant effect of GENOTYPE $(\mathrm{F}(1,59)=8.27 ; p<0.01)$, the GENOTYPE $\times$ DRUG interaction term was also significant $(\mathrm{F}(2,59)=17.49 ; p<0.001)$, reflecting the decreased PPI after cocaine treatment in wildtype mice and the increased PPI after cocaine treatment in DAT KO mice. No other effects were statistically significant, including DRUG, GENOTYPE $\times$ INTENSITY, or DRUG $\times$ INTENSITY. Post hoc comparisons at each treated group are shown in Figure 1.

Startle reactivity was not significantly affected by either GENOTYPE or DRUG treatment (Table 1). There was also no significant GENOTYPE $\times$ DRUG interaction.

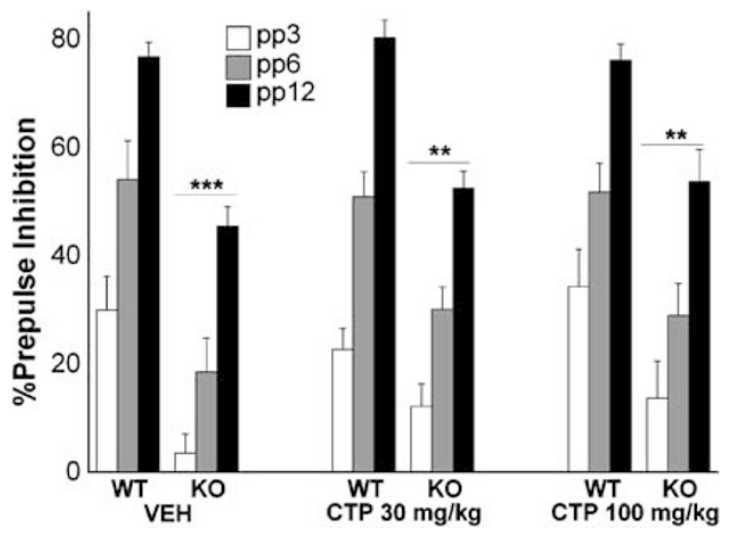

Figure 4 Prepulse inhibition (PPI) in wild-type mice (WT) and dopamine transporter knockout mice (KO) after administration of vehicle (VEH), $30 \mathrm{mg} / \mathrm{kg}$ citalopram (CTP), or $100 \mathrm{mg} / \mathrm{kg}$ citalopram (CTP); KO VEH displayed significantly reduced PPI compared with WT VEH. CTP (30 or $100 \mathrm{mg} / \mathrm{kg}$ ) treatment did not significantly affect PPI in WT VEH or $\mathrm{KO} \mathrm{VEH}$. \%PPI values represent mean \pm SEM. *** $p<0.0$ I, **** $p<0.00$ I compared with WT VEH.

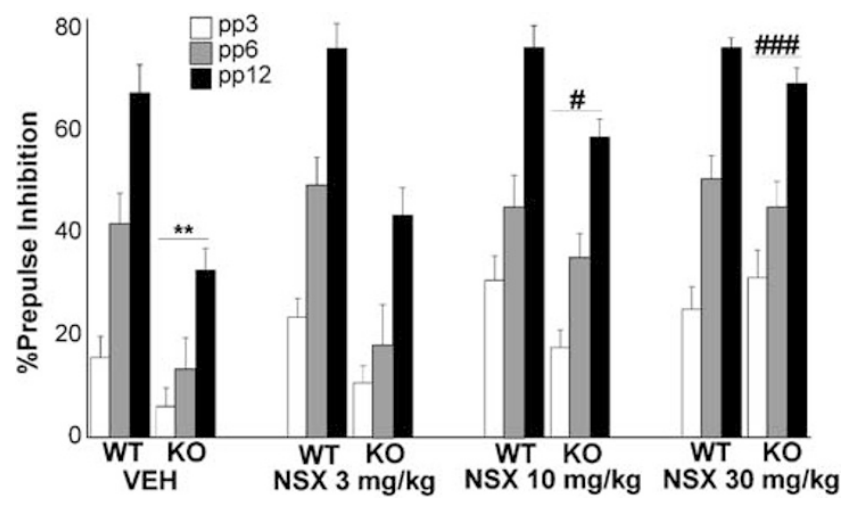

Figure 5 Prepulse inhibition (PPI) in wild-type mice (WT) and dopamine transporter knockout mice (KO) after administration of vehicle (VEH), $3 \mathrm{mg} / \mathrm{kg}$ nisoxetine (NSX), $10 \mathrm{mg} / \mathrm{kg}$ nisoxetine (NSX), or $30 \mathrm{mg} / \mathrm{kg}$ nisoxetine (NSX); KO VEH displayed significantly reduced PPI compared with WT VEH. NSX (I 0 or $30 \mathrm{mg} / \mathrm{kg}$ ) treatment significantly reversed PPI deficits in $\mathrm{KO} V E H$ without significantly affecting PPI in WT VEH. \%PPI values represent mean \pm SEM. *** $<0.0$ I compared with WT VEH; ${ }^{\#} p<0.05, \# \# p<0.00$ I compared with $\mathrm{KO} \mathrm{VEH}$.

\section{Effects of Methylphenidate on PPI and Acoustic Startle}

ANOVA of baseline data revealed a significant GENOTYPE effect on PPI $(\mathrm{F}(1,17)=42.51 ; p<0.001)$; DAT KO mice displayed significantly reduced levels of PPI compared to wild-type mice after saline treatment (Figure 2). Methylphenidate $(30$ and $60 \mathrm{mg} / \mathrm{kg})$, another non-specific monoaminergic transport inhibitor, reduced levels of PPI in wild-type mice compared to VEH treatment. By contrast, methylphenidate $(60 \mathrm{mg} / \mathrm{kg})$ significantly increased PPI in DAT KO mice when compared to VEH treatment (Figure 2). ANOVA displayed significant effects of DRUG $(F(2,62)=$ 5.05; $p<0.01)$ and a DRUG $\times$ GENOTYPE interaction $(\mathrm{F}(2,62)=25.10 ; p<0.01)$. These statistically significant effects reflected the reduction of PPI by methylphenidate in wild-type mice and the increase of PPI by methylphenidate in DAT KO mice. There were no significant overall effects of GENOTYPE, GENOTYPE $\times$ INTENSITY, 
Table I Effects of Drug Treatment on Acoustic Startle Reactivity

\begin{tabular}{|c|c|c|}
\hline & Wild type & ко \\
\hline \multicolumn{3}{|l|}{ Cocaine } \\
\hline Vehicle & $113.2 \pm 29.6$ & $84.7 \pm 21.9$ \\
\hline $30 \mathrm{mg} / \mathrm{kg}$ & $125.2 \pm 16.9$ & $139.5 \pm 16.8$ \\
\hline $60 \mathrm{mg} / \mathrm{kg}$ & $61.7 \pm 22.7$ & $115.7 \pm 26.0$ \\
\hline \multicolumn{3}{|c|}{ Methylphenidate } \\
\hline Vehicle & $106.7 \pm 29.0$ & $89.0 \pm 23.0$ \\
\hline $30 \mathrm{mg} / \mathrm{kg}$ & $104.5 \pm 19.3$ & $95.0 \pm 16.2$ \\
\hline $60 \mathrm{mg} / \mathrm{kg}$ & $58.2 \pm 11.0$ & $84.0 \pm 16.0$ \\
\hline \multicolumn{3}{|l|}{ Fluoxetine* } \\
\hline Vehicle & $169.9 \pm 20.0$ & $101.8 \pm 16.9$ \\
\hline $10 \mathrm{mg} / \mathrm{kg}$ & $230.3 \pm 27.0$ & $173.2 \pm 19.4$ \\
\hline $30 \mathrm{mg} / \mathrm{kg}$ & $254.5 \pm 58.7$ & $237.5 \pm 38.6$ \\
\hline \multicolumn{3}{|l|}{ Citalopram*** } \\
\hline Vehicle & $116.2 \pm 12.2$ & $95.5 \pm 18.7$ \\
\hline $30 \mathrm{mg} / \mathrm{kg}$ & $254.3 \pm 35.3^{\#}$ & $196.4 \pm 18.9$ \\
\hline 100 mg/kg & $192.1 \pm 27.4$ & $154.6 \pm 28.8$ \\
\hline \multicolumn{3}{|l|}{ Nisoxetine } \\
\hline Vehicle & $147.7 \pm 31.3$ & $125.1 \pm 28.5$ \\
\hline $3 \mathrm{mg} / \mathrm{kg}$ & $|33.7 \pm| 4.5$ & $115.4 \pm 18.5$ \\
\hline $10 \mathrm{mg} / \mathrm{kg}$ & $138.8 \pm \mid 4.4$ & $132.8 \pm 23.1$ \\
\hline $30 \mathrm{mg} / \mathrm{kg}$ & $139.9 \pm 23.7$ & $105.0 \pm 10.8$ \\
\hline
\end{tabular}

Values (arbitrary units) represent mean startle magnitude \pm SEM. KO, dopamine transporter knockout mice.

$* p<0.05, * * p<0.01$ : there was a significant main effect of treatment on acoustic startle reactivity; ${ }^{\#} p<0.01$, compared with wild-type vehicle.

or DRUG $\times$ INTENSITY. The results of post hoc comparisons for each treated-group are shown in Figure 2.

Startle reactivity was not significantly affected by GENOTYPE or DRUG treatment (Table 1), nor was there a significant DRUG $\times$ GENOTYPE interaction.

\section{Effects of Fluoxetine on PPI and Acoustic Startle}

ANOVA of baseline data revealed a significant GENOTYPE effect on PPI $(F(1,18)=10.53 ; p<0.01)$; following saline treatment, DAT KO mice displayed significantly reduced levels of PPI compared to wild-type mice (Figure 3). Fluoxetine $(30 \mathrm{mg} / \mathrm{kg})$, a selective SERT inhibitor, increased PPI in DAT KO mice without significantly affecting PPI in wild-type mice (Figure 3). In the ANOVA, there were significant effects of DRUG $(\mathrm{F}(2,60)=6.31 ; p<0.01)$, GENOTYPE $(\mathrm{F}(1,60)=17.19 ; p<0.001)$, DRUG $\times$ INTENSITY $(F(4,120)=2.66 ; p<0.05)$, and GENOTYPE $\times$ INTENSITY $(\mathrm{F}(2,120)=3.73 ; p<0.05)$, reflecting the increase in PPI only in DAT KO mice, but not in wild-type mice. There was no significant interaction between GENOTYPE and DRUG. The results of post hoc comparisons are shown in Figure 3.
There was no significant main effect of GENOTYPE on the magnitude of acoustic startle, but there was a significant main effect of DRUG $(\mathrm{F}(2,60)=4.69 ; p<0.05)$. Fluoxetine significantly increased the acoustic startle response independent of GENOTYPE (Table 1), as indicated by the main effect of DRUG in the absence of a significant DRUG $\times$ GENOTYPE interaction.

\section{Effects of Citalopram on PPI and Acoustic Startle}

ANOVA of baseline data revealed a significant GENOTYPE effect on PPI $(\mathrm{F}(1,18)=27.97 ; p<0.001)$; Once again, DAT KO mice displayed significantly reduced levels of PPI compared to wild-type mice after saline (Figure 4). Citalopram (30 and $100 \mathrm{mg} / \mathrm{kg}$ ), a highly selective SERT inhibitor, did not significantly affect PPI in wild-type or DAT KO mice (Figure 4). Overall, there was a significant effect of GENOTYPE $(\mathrm{F}(1,55)=50.39 ; p<0.001)$ in the ANOVA, but none of the other factors were significantly different, including DRUG, DRUG $\times$ GENOTYPE, DRUG $\times$ INTENSITY, and GENOTYPE $\times$ INTENSITY. The results of post hoc comparisons are shown in Figure 4.

Although there was no significant main effect of GENOTYPE on the magnitude of the acoustic startle response, there was a significant main effect of DRUG $(\mathrm{F}(2,55)=11.41 ; p<0.001)$, but no significant GENOTYPE $\times$ DRUG interaction. Thus, the citalopram treatment significantly enhanced the acoustic startle response independent of GENOTYPE (Table 1).

\section{Effects of Nisoxetine on PPI and Acoustic Startle}

ANOVA of baseline data revealed a significant GENOTYPE effect on PPI $(\mathrm{F}(1,21)=17.03 ; p<0.001)$; as before, PPI was reduced in DAT KO mice after saline injection compared to wild-type mice (Figure 5). Nisoxetine (10 and $30 \mathrm{mg} / \mathrm{kg}$ ), a selective NET inhibitor, significantly increased PPI in DAT KO mice without significantly affecting PPI in wild-type mice (Figure 5). In the ANOVA, there was a significant main effect of GENOTYPE $(\mathrm{F}(1,89)=32.00 ; p<0.001)$ and DRUG $(\mathrm{F}(3,89)=8.96 ; p<0.001)$, as well as a significant GENOTYPE $\times$ DRUG interaction $(\mathrm{F}(3,89)=3.63 ; p<0.05)$ reflecting this differential response to nisoxetine in DAT KO mice in the absence of any response in wild-type mice. The effects of GENOTYPE varied across prepulse intensities so that there was a significant GENOTYPE $\times$ INTENSITY interaction $(\mathrm{F}(2,178)=12.70 ; p<0.001)$. However, the effects of nisoxetine were consistent across prepulse intensities so there was no significant DRUG $\times$ INTENSITY interaction. The results of post hoc comparisons are shown in Figure 5.

The magnitude of the acoustic startle response was not affected by GENOTYPE or DRUG (Table 1). In the ANOVA, there was no significant effect of GENOTYPE or DRUG, nor was there a significant GENOTYPE $\times$ DRUG interaction.

\section{DISCUSSION}

The results from these experiments demonstrate that cocaine and methylphenidate ameliorate PPI deficits in DAT KO mice. As these mice lack DAT, one of the main pharmacological targets of these drugs, it is likely that 
NET or SERT, the other main molecular targets of psychostimulants, mediate these residual effects. Current results are most consistent with the idea that the PPInormalizing effects of these drugs are chiefly mediated via NET. Cocaine and methylphenidate share the ability to potently inhibit both NET and DAT, but since methylphenidate displays very lower affinity for SERT (Gatley et al, 1996), SERT blockade is not likely to mediate psychostimulant effects on PPI in DAT KO mice. Furthermore, the highly selective NET inhibitor nisoxetine, administered alone, also reversed the PPI deficits in DAT KO mice. By contrast, the highly selective SERT inhibitor citalopram failed to reverse these deficits, even at a high dose $(100 \mathrm{mg} /$ $\mathrm{kg})$. There was significant amelioration of PPI deficits in DAT KO mice produced by the less selective SERT inhibitor fluoxetine. A comparison of these drugs is highly informative; although the affinity of fluoxetine and citalopram for SERT is not different (Owens et al, 2001), fluoxetine has about 10-fold higher affinity than citalopram for NET (Hughes and Stanford, 1996; Owens et al, 2001). Alternatively, fluoxetine has serotonin $5-\mathrm{HT}_{2 \mathrm{~A}}$ or $5-\mathrm{HT}_{2 \mathrm{C}}$ receptor antagonistic effects that are not shared with citalopram (Koch et al, 2002) and could lead to the fluoxetine effects on the PPI deficits that we observe in DAT KO mice, as has been observed for 5- $\mathrm{HT}_{2 \mathrm{~A}}$ antagonists (Barr et al, 2004).

The selective SERT inhibitors fluoxetine and citalopram significantly increased the acoustic startle response of C57BL/129Sv hybrid mice, independent of genotype. Although these increases are likely to be mediated through SERT blockade, no enhancement of acoustic startle response was previously observed in rats after SERT blockade (Martinez and Geyer, 1997; Pouzet et al, 2005), although decreased startle habituation has been reported in rats (Geyer and Tapson, 1988). Analyses of startle data after citalopram and fluoxetine revealed increased startle magnitude but no DRUG $\times$ BLOCK interactions indicating no effect on habituation. However, analyses of each block revealed significant effects of fluoxetine only in later blocks (from second to fourth block), but significant effects of citalopram throughout (data not shown). Thus, based on this analysis, citalopram might cause an alteration in general startle reactivity, but fluoxetine might affect startle habituation. Conceivably, these effects might be somewhat different from those in rats, given the substantial differences in startle and PPI indices that have been documented based on strain and species background (Ralph and Caine, 2005; Swerdlow et al, 2005). Serotonergic agents in mice exhibit strain differences in PPI, habituation, and startle reactivity (Dulawa and Geyer, 2000). The serotonin releaser methylene-dioxy-methamphetamine disrupts PPI in rats, but increases PPI in humans (Vollenweider et al, 1999; Liechti et al, 2001). Ayahuasca, containing 5- $\mathrm{HT}_{2 \mathrm{~A} / 2 \mathrm{C}}$ agonistic compounds, has no effect on PPI, habituation, and startle reactivity in humans (Riba et al, 2002), although various serotonergic drugs affect PPI or startle habituation in rats (for a review, see Geyer et al, 1990; Geyer, 1998).

Methylphenidate and even more selective norepinephrine reuptake inhibitors can be clinically effective treatments for ADHD (Eiland and Guest, 2004). The superficial similarities of some phenotypes found in DAT KO mice to some of the motor symptoms of ADHD have suggested to some authors that DAT KO mice provide an animal model for this disorder. Indeed, these mice do display reductions in hyperlocomotion after treatment with psychostimulants under some conditions (Gainetdinov et al, 1999). Obviously, attentional and cognitive components of ADHD symptomatology may not be reflected by this model. It remains to be seen if PPI deficits induced by psychostimulants or dopaminergic overactivity (Wilkinson et al, 1994; Barr et al, 2004) reflect the sort of attentional deficits observed in ADHD. Nonetheless, it is interesting to note that selective serotonin reuptake inhibitors (SSRIs) are reported to be ineffective in ADHD (Findling, 1996), even though fluoxetine appears to reduce hyperactivity in DAT KO mice (Gainetdinov et al, 1999). In the present experiments, we found that the same class of drugs, selective noradrenaline reuptake inhibitors (NRIs), that has been recently shown to effectively treat ADHD symptoms (for a review, see Christman et al, 2004) can also normalize PPI function in DAT KO mice. Similarly, but in contrast to some previous observations (Gainetdinov et al, 1999), we have found that nisoxetine, an NRI, can reduce hyperactivity in DAT KO mice, while citalopram, an SSRI, does not (Fukushima and Sora, unpublished data). These results indicate that NET may be the critical molecular target for psychostimulantinduced normalization of PPI in this model.

Our recent microdialysis studies demonstrate enhanced DA levels in the prefrontal cortex (PFc), but not the nucleus accumbens (NAc), after systemic administration of cocaine (Shen et al, 2004) and methylphenidate (Shen and Sora, unpublished data) in DAT KO mice. By contrast, wild-type mice exhibit changes in both structures. Furthermore, systemic nisoxetine and fluoxetine administration in DAT KO mice enhances extracellular DA concentrations in PFc (Shen and Sora, unpublished data). Interestingly, systemic citalopram administration, which differs from fluoxetine in its effects on serotonin receptors and NET, did not have this effect (Shen and Sora, unpublished data). Atomoxetine, an NRI, can also increase PFc DA levels in rats, and it has been suggested that the atomoxetine-induced increase of catecholamines in PFc mediates the therapeutic effects of atomoxetine in ADHD (Bymaster et al, 2002).

Since DA has higher affinity for NET than for DAT (Eshleman et al, 1999) and PFc DAT densities are relatively low (Sesack et al, 1998) in comparison with PFc NET densities (Schroeter et al, 2000), PFc DA uptake may depend more significantly on NET (Carboni et al, 1990; Moron et al, 2002). In caudate putamen $(\mathrm{CPu})$ and NAc, where DAT densities predominate, DA uptake is likely to depend primarily on DAT (Moron et al, 2002). Cocaine, methylphenidate, and nisoxetine, all NET blockers, could thus increase dopaminergic tone in PFc while leaving NAc DA levels virtually unchanged in DAT KO mice.

Effects of DAT KO on PPI are consistent with effects of excess synaptic DA produced in other ways, as assessed in other brain regions. For example, PPI is impaired by DA infusion into the NAc or anteromedial striatum (Swerdlow et al, 1992). On the other hand, DA in PFc appears to exert inhibitory control on NAc DA systems (Banks and Gratton, 1995). Depletion of prefrontal DA by 6-hydroxydopamine (6-OHDA), or infusion of D1 or D2 antagonists into the PFc, reduces PPI (Bubser and Koch, 1994; Ellenbroek et al, 1996). Reduced DA-mediated disinhibition of descending glutamatergic fibers could result in subcortical increases in 
DA neurotransmission in the NAc (Swerdlow et al, 2001). Increased endogenous DA activity in PFc, resulting from inhibition of DA transport via NET, could possibly normalize PPI deficits caused by DA overactivity in NAc. Differences in the ratio between psychostimulant effects on DA uptake in PFc vs NAc in DAT KO mice compared to wild-type mice might underlie the profound differences in the effects of psychostimulants on PPI in these mice.

In conclusion, the normalization of the PPI deficits in DAT KO mice after administration of cocaine, methylphenidate, and nisoxetine are most likely to be mediated by NET inhibition. Since the affinities for NET binding were decreased in the order: nisoxetine $\gg$ methylphenidate $\geqslant$ cocaine (Gatley et al, 1996), the effective doses for PPI improvement in DAT KO mice may be consistent with their ability to inhibit NET. Microdialysis (Shen et al, 2004) and current results, taken together, suggest that enhanced PFc extracellular DA produced via NET blockade may mediate normalization of PPI in DAT KO mice under these circumstances. However, methylphenidate does require a high dose to ameliorate PPI deficits in DAT KO mice, compared to the clinically effective dose for the treatment of ADHD. The therapeutic mechanism of ADHD might not be explained solely by enhanced DA in PFc resulting from NET inhibition. Other mechanisms might be involved, such as the ability of methylphenidate to affect cognitive behavior through noradrenergic $\alpha 2$ adrenoceptors in the $\mathrm{PFC}$ (Arnsten and Dudley, 2005). Additionally, increases in PFc DA after cocaine are observed from after a $10 \mathrm{mg} / \mathrm{kg}$ dose (Shen et al, 2004), but cocaine requires $60 \mathrm{mg} / \mathrm{kg}$ to affect PPI in DAT KO mice. Thus, despite the substantial evidence given here supporting the role of NET in the mechanism of action of psychostimulants in the normalization of PPI deficits in DAT KO mice, it is not a complete explanation. The validity of DAT KO mice as a model of ADHD is limited by our understanding of the underlying biochemical basis of that disorder; thus, enhanced DA in PFc might only give a partial explanation for the therapeutic mechanisms of psychostimulants in ADHD. Nonetheless, NET blockers including methylphenidate and cocaine can normalize the PPI deficits in DAT KO mice, and, to the extent that DAT KO mice constitute an animal model of features of ADHD, such mechanisms could also underlie the therapeutic benefits of both psychostimulants and nonpsychostimulant NET blockers such as atomoxetine in ADHD.

\section{ACKNOWLEDGEMENTS}

We thank Ms Kayo Ohmi, Ms Harumi Hata, and Ms Maki Naka for their assistance. This study was supported by a Grant-in-Aid for Health Science Research, the Research on Psychiatric and Neurological Diseases from the Ministry of Health, Labor and Welfare of Japan; by Grants-in-Aid for Scientific Research (Nos. 15029204, 16015209, 17390315, 17022007), from the Ministry of Education, Culture, Sports, Science and Technology of Japan; and by the Mitsubishi Pharma Research Foundation.

\section{REFERENCES}

Arnsten AF, Dudley AG (2005). Methylphenidate improves prefrontal cortical cognitive function through alpha2 adreno- ceptor and dopamine D1 receptor actions: relevance to therapeutic effects in attention deficit hyperactivity disorder. Behav Brain Funct 1: 2.

Banks KE, Gratton A (1995). Possible involvement of medial prefrontal cortex in amphetamine-induced sensitization of mesolimbic dopamine function. Eur J Pharmacol 282: 157-167.

Barr AM, Lehmann-Masten V, Paulus M, Gainetdinov RR, Caron MG, Geyer MA (2004). The selective serotonin-2A receptor antagonist M100907 reverses behavioral deficits in dopamine transporter knockout mice. Neuropsychopharmacology 29: 221-228.

Braff DL, Geyer MA, Swerdlow NR (2001). Human studies of prepulse inhibition of startle: normal subjects, patient groups, and pharmacological studies. Psychopharmacology (Berl) 156: 234-258.

Bubser M, Koch M (1994). Prepulse inhibition of the acoustic startle response of rats is reduced by 6-hydroxydopamine lesions of the medial prefrontal cortex. Psychopharmacology (Berl) 113: 487-492.

Bymaster FP, Katner JS, Nelson DL, Hemrick-Luecke SK, Threlkeld PG, Heiligenstein JH et al (2002). Atomoxetine increases extracellular levels of norepinephrine and dopamine in prefrontal cortex of rat: a potential mechanism for efficacy in attention deficit/hyperactivity disorder. Neuropsychopharmacology 27: 699-711.

Carboni E, Tanda GL, Frau R, Di Chiara G (1990). Blockade of the noradrenaline carrier increases extracellular dopamine concentrations in the prefrontal cortex: evidence that dopamine is taken up in vivo by noradrenergic terminals. J Neurochem 55: 1067-1070.

Christman AK, Fermo JD, Markowitz JS (2004). Atomoxetine, a novel treatment for attention-deficit-hyperactivity disorder. Pharmacotherapy 24: 1020-1036.

Dulawa SC, Geyer MA (2000). Effects of strain and serotonergic agents on prepulse inhibition and habituation in mice. Neuropharmacology 39: 2170-2179.

Dulawa SC, Hen R, Scearce-Levie K, Geyer MA (1997). Serotonin1B receptor modulation of startle reactivity, habituation, and prepulse inhibition in wild-type and serotonin1B knockout mice. Psychopharmacology (Berl) 132: 125-134.

Eiland LS, Guest AL (2004). Atomoxetine treatment of attentiondeficit/hyperactivity disorder. Ann Pharmacother 38: 86-90.

Ellenbroek BA, Budde S, Cools AR (1996). Prepulse inhibition and latent inhibition: the role of dopamine in the medial prefrontal cortex. Neuroscience 75: 535-542.

Eshleman AJ, Carmolli M, Cumbay M, Martens CR, Neve KA, Janowsky A (1999). Characteristics of drug interactions with recombinant biogenic amine transporters expressed in the same cell type. J Pharmacol Exp Ther 289: 877-885.

Findling RL (1996). Open-label treatment of comorbid depression and attentional disorders with co-administration of serotonin reuptake inhibitors and psychostimulants in children, adolescents, and adults: a case series. J Child Adolesc Psychopharmacol 6: $165-175$.

Fone KC, Nutt DJ (2005). Stimulants: use and abuse in the treatment of attention deficit hyperactivity disorder. Curr Opin Pharmacol 5: 87-93.

Gainetdinov RR, Wetsel WC, Jones SR, Levin ED, Jaber M, Caron MG (1999). Role of serotonin in the paradoxical calming effect of psychostimulants on hyperactivity. Science 283: 397-401.

Gatley SJ, Pan D, Chen R, Chaturvedi G, Ding YS (1996). Affinities of methylphenidate derivatives for dopamine, norepinephrine and serotonin transporters. Life Sci 58: 231-239.

Geyer MA (1998). Behavioral studies of hallucinogenic drugs in animals: implications for schizophrenia research. Pharmacopsychiatry 31(Suppl 2): 73-79.

Geyer MA, Dulawa SC (2003). Assessment of murine startle reactivity, prepulse inhibition, and habituation. In: Crawley J, 
Gerfen C (eds). Current Protocols in Neuroscience. John Wiley \& Sons Inc.: New Jersey. pp 8.17.1-8.17.15.

Geyer MA, Swerdlow NR, Mansbach RS, Braff DL (1990). Startle response models of sensorimotor gating and habituation deficits in schizophrenia. Brain Res Bull 25: 485-498.

Geyer MA, Tapson GS (1988). Habituation of tactile startle is altered by drugs acting on serotonin-2 receptors. Neuropsychopharmacology 1: 135-147.

Hoffman HS, Ison JR (1980). Reflex modification in the domain of startle: I. Some empirical findings and their implications for how the nervous system processes sensory input. Psychol Rev 87: 175-189.

Hughes ZA, Stanford SC (1996). Increased noradrenaline efflux induced by local infusion of fluoxetine in the rat frontal cortex. Eur J Pharmacol 317: 83-90.

Koch S, Perry KW, Nelson DL, Conway RG, Threlkeld PG, Bymaster FP (2002). R-fluoxetine increases extracellular DA, $\mathrm{NE}$, as well as 5-HT in rat prefrontal cortex and hypothalamus: an in vivo microdialysis and receptor binding study. Neuropsychopharmacology 27: 949-959.

Laruelle M, Abi-Dargham A (1999). Dopamine as the wind of the psychotic fire: new evidence from brain imaging studies. J Psychopharmacol 13: 358-371.

Liechti ME, Geyer MA, Hell D, Vollenweider FX (2001). Effects of MDMA (ecstasy) on prepulse inhibition and habituation of startle in humans after pretreatment with citalopram, haloperidol, or ketanserin. Neuropsychopharmacology 24: 240-252.

Martinez DL, Geyer MA (1997). Characterization of the disruptions of prepulse inhibition and habituation of startle induced by alpha-ethyltryptamine. Neuropsychopharmacology 16: 246-255.

Moron JA, Brockington A, Wise RA, Rocha BA, Hope BT (2002). Dopamine uptake through the norepinephrine transporter in brain regions with low levels of the dopamine transporter: evidence from knock-out mouse lines. J Neurosci 22: 389-395.

Orjales A, Mosquera R, Toledo A, Pumar MC, Garcia N, Cortizo L et al (2003). Syntheses and binding studies of new [(aryl) (aryloxy)methyl]piperidine derivatives and related compounds as potential antidepressant drugs with high affinity for serotonin (5-HT) and norepinephrine (NE) transporters. J Med Chem 46: $5512-5532$.

Owens MJ, Knight DL, Nemeroff CB (2001). Second-generation SSRIs: human monoamine transporter binding profile of escitalopram and $R$-fluoxetine. Biol Psychiatry 50: 345-350.

Paczkowski FA, Bryan-Lluka LJ (2002). Amino acids involved in differences in the pharmacological profiles of the rat and human noradrenaline transporters. Naunyn Schmiedebergs Arch Pharmacol 365: 312-317.

Pouzet B, Andersen MP, Hogg S (2005). Effects of acute treatment with antidepressant drugs on sensorimotor gating deficits in rats. Psychopharmacology (Berl) 178: 9-16.
Ralph RJ, Caine SB (2005). Dopamine D1 and D2 agonist effects on prepulse inhibition and locomotion: comparison of SpragueDawley rats to Swiss-Webster, 129X1/SvJ, C57BL/6J, and DBA/2J mice. J Pharmacol Exp Ther 312: 733-741.

Ralph RJ, Paulus MP, Fumagalli F, Caron MG, Geyer MA (2001). Prepulse inhibition deficits and perseverative motor patterns in dopamine transporter knock-out mice: differential effects of D1 and D2 receptor antagonists. J Neurosci 21: 305-313.

Riba J, Rodriguez-Fornells A, Barbanoj MJ (2002). Effects of ayahuasca on sensory and sensorimotor gating in humans as measured by P50 suppression and prepulse inhibition of the startle reflex, respectively. Psychopharmacology (Berl) 165: $18-28$.

Schroeter S, Apparsundaram S, Wiley RG, Miner LH, Sesack SR, Blakely RD (2000). Immunolocalization of the cocaine- and antidepressant-sensitive 1-norepinephrine transporter. J Comp Neurol 420: 211-232.

Sesack SR, Hawrylak VA, Guido MA, Levey AI (1998). Cellular and subcellular localization of the dopamine transporter in rat cortex. Adv Pharmacol 42: 171-174.

Shen HW, Hagino Y, Kobayashi H, Shinohara-Tanaka K, Ikeda K, Yamamoto $\mathrm{H}$ et al (2004). Regional differences in extracellular dopamine and serotonin assessed by in vivo microdialysis in mice lacking dopamine and/or serotonin transporters. Neuropsychopharmacology 29: 1790-1799.

Sora I, Wichems C, Takahashi N, Li XF, Zeng Z, Revay R et al (1998). Cocaine reward models: conditioned place preference can be established in dopamine- and in serotonin-transporter knockout mice. Proc Natl Acad Sci USA 95: 7699-7704.

Swerdlow NR, Caine SB, Geyer MA (1992). Regionally selective effects of intracerebral dopamine infusion on sensorimotor gating of the startle reflex in rats. Psychopharmacology (Berl) 108: 189-195.

Swerdlow NR, Geyer MA, Braff DL (2001). Neural circuit regulation of prepulse inhibition of startle in the rat: current knowledge and future challenges. Psychopharmacology (Berl) 156: $194-215$.

Swerdlow NR, Kuczenski R, Goins JC, Crain SK, Ma LT, Bongiovanni MJ et al (2005). Neurochemical analysis of rat strain differences in the startle gating-disruptive effects of dopamine agonists. Pharmacol Biochem Behav 80: 203-211.

Vollenweider FX, Remensberger S, Hell D, Geyer MA (1999). Opposite effects of 3, 4-methylenedioxymethamphetamine (MDMA) on sensorimotor gating in rats versus healthy humans. Psychopharmacology (Berl) 143: 365-372.

Wilkinson LS, Killcross SS, Humby T, Hall FS, Geyer MA, Robbins TW (1994). Social isolation in the rat produces developmentally specific deficits in prepulse inhibition of the acoustic startle response without disrupting latent inhibition. Neuropsychopharmacology 10: 61-72. 